Revista Multidisciplinar do Nordeste Mineiro, v.1 2019/02

ISSN 2178-6925

\title{
A RELEVÂNCIA DO ENSINO DE ARTES VISUAIS NOS ANOS INICIAIS DO ENSINO FUNDAMENTAL
}

\section{THE RELEVANCE OF VISUAL ARTS EDUCATION IN THE EARLY YEARS OF FUNDAMENTAL EDUCATION}

\begin{abstract}
Maísa de Sousa Santos Lima Amorim
Pedagoga, formada na Faculdade Presidente Antônio Carlos de Teófilo Otoni/MG. E-mail: maisaamorimms@gmail.com

Augusto de Morais Pinho

Graduado em Desenho e Plástica, Letras, Pedagogia, Especialização em Psicopedagogia, Professor do Curso de Pedagogia da Faculdade Presidente Antônio Carlos de Teófilo Otoni MG E-mail: academico@unipacto.com.br.
\end{abstract}

\section{Resumo}

Distintos estudos mostram que o ensino de artes visuais possui objetivos claros e significativos, principalmente na educação nos anos iniciais do ensino fundamental, desenvolvendo aspectos, como aumento da autoestima, do cognitivo, sensibilidade, percepção, expressividade, espontaneidade, consciência de si mesmo e do outro e das diversas culturas. $\mathrm{O}$ ensino de artes visuais pode desenvolver no aluno aspectos sociais, bem como auxilia-lo na construção do conhecimento permitindo-o compreender a sua realidade e torna-lo criativo diante de seus desafios. Portanto o presente artigo objetivou conhecer e compreender a atuação de professores que ministram o ensino de Artes Visuais, identificar e propor metodologias que busquem valorizar o ensino de Artes visuais nos anos iniciais do ensino fundamental, como instrumento que proporcione o desenvolvimento da criança. Buscou-se reunir dados/informações com o propósito de responder aos seguintes questionamentos: 0 ensino de artes visuais pode contribuir para o desenvolvimento da criança nos anos iniciais do ensino fundamental? Os profissionais que ministram esta disciplina são qualificados? O ensino de Artes visuais é valorizado ou visto como um mero passatempo? A metodologia foi uma revisão literária com análises de artigos científicos, dissertações de mestrado, livros de importantes autores a fim de nos levar a uma reflexão sobre o ensino de artes visuais, dando ênfase a sua relevância. Em termo de resultados a pesquisa sinaliza que o ensino de Artes visuais tem um papel significativo relacionado ao desenvolvimento da criança, propiciando à aprendizagem, criatividade, imaginação, sensibilidade, percepção de si mesmo e do outro, possibilitando também o conhecimento relacionado à cultura do ambiente em que está inserido, favorecendo o desenvolvimento de aspectos sociais, tornando-o individuo critico, pensante capaz de se relacionar e de maneira criativa resolver possíveis desafios. 
Palavras-chave: Artes visuais. Anos iniciais. Metodologias. Preparo profissional.

\begin{abstract}
Many studies show that the visual arts teaching has clear and important objectives, mainly in the first grades of elementary school, developing aspects such like increase of the selfsteem, cognition, sensibility, perception, expressiveness, spontaneity, self and social conscience and different cultures conscience. Visual arts teaching can develop students in social matters and help them in the construction of knowledge, allowing the comprehension of their reality and turning them into creative children in front of their problems. Therefore this article aims to know and to understand about teachers' acting that administer visual arts teaching, identify and proposed methods that value this teaching in the elementary school, just like the child development through it, seeking to collect dates/information to respond to the following inquiry of this research: can the visual arts teaching contribute to the child developing in the first grades of the elementary school? Are the professionals that administer this subject qualified? Is the visual arts teaching valued or just a simple pastime? To achieve this survey's objectives a literature review was done based on analysis of scientific articles, master's dissertation and books written by important authors. Taking us to a reflection about the visual arts teaching, emphasizing its importance. In results concerns this research shows that the visual arts teaching plays a significant role related to the child development, providing creativity, imagination, sensibility, perception of themselves and social perception to the learning process. It also propitiate the knowledge related to the culture where the children are inserted, just like other cultures, promoting the development in social aspects, turning them into critical and intellectual people who's able to maintain relationships with others and creatively solve their problems.
\end{abstract}

Key words: Visual arts. Early years. Methods. Professional training.

\title{
1 Introdução
}

Distintos estudos apontam o ensino de artes visuais como instrumento relevante na educação nos anos iniciais do ensino fundamental, desenvolvendo aspectos, como aumento da autoestima, do cognitivo, sensibilidade, percepção, expressividade, espontaneidade, consciência de si mesmo e do outro e das diversas culturas. $\mathrm{O}$ ensino de artes visuais pode desenvolver no aluno aspectos sociais, bem como auxilia-lo na construção do conhecimento permitindo-o compreender a sua realidade e torna-lo criativo diante de seus problemas. Essa pesquisa tem como objetivo principal, conhecer e compreender sobre a atuação de professores que ministram esta disciplina, identificar e propor metodologias que busquem valorizar o 
ensino de Artes visuais nos anos iniciais do ensino fundamental, como também o desenvolvimento da criança através dela.

Buscou-se reunir dados/informações com o propósito de responder aos seguintes problemas da pesquisa: o ensino de artes visuais pode contribuir para o desenvolvimento da criança nos anos iniciais do ensino fundamental? Os profissionais que ministram esta disciplina são qualificados? $O$ ensino de Artes visuais é valorizado ou visto como um mero passatempo?

Foi através desses questionamentos e ao dar inicio aos estágios do curso de pedagogia da Faculdade Presidente Antônio Carlos de Teófilo Otoni que surgiu o desejo de estudar a temática apresentada neste trabalho, visando compreender a forma que o ensino de Artes Visuais vem sendo ministrado nas salas de aula nos dias de hoje.

O desenvolvimento do trabalho contou com um breve estudo sobre a valorização do ensino de artes visuais, a seguir buscou-se identificar elementos que busquem a valorização do ensino de artes visuais e por fim, discutiu-se sobre o preparo profissional e o poder do desenvolvimento através da Arte.

Para atingir os objetivos da pesquisa foi realizada uma revisão literária com análises de artigos científicos, dissertações de mestrado, teses de doutorado, livros de importantes autores como Ana Mae Barbosa (1989); Miriam Celeste Martins (1998) Gisa Picosque (1998) entre outros autores, a fim de nos levar a uma reflexão sobre o ensino de artes visuais, dando ênfase a sua relevância nos anos iniciais do ensino fundamental.

\section{Valorização do ensino de artes visuais}

Conforme os PCNs (Parâmetros Curriculares Nacionais), (1997) o conceito de Artes Visuais é muito vasto e abrange varias modalidades artísticas, como pintura, colagem, escultura, modelagem, desenho, gravura, arquitetura, desenho industrial, entre outras é uma linguagem que provoca uma experiência estética visual, está diretamente ligada à imagem. As artes visuais, além das formas tradicionais incluem outras modalidades que resultam dos avanços tecnológicos e transformações estéticas a partir da modernidade (fotografia, artes gráficas, cinema, televisão, vídeo, computação, performance).

Cada uma dessas visualidades é utilizada de modo particular e em várias possibilidades de combinações entre imagens, por intermédio das quais os alunos 
podem expressar-se e comunicar-se entre si de diferentes maneiras. PCNs (1997, p.

45). A BNCC também destaca que:

\begin{abstract}
As Artes visuais são os processos e produtos artísticos e culturais, nos diversos tempos históricos e contextos sociais, que têm a expressão visual como elemento de comunicação. Essas manifestações resultam de explorações plurais e transformações de materiais, de recursos tecnológicos e de apropriações da cultura cotidiana. As Artes visuais possibilitam aos alunos explorar múltiplas culturas visuais, dialogar com as diferenças e conhecer outros espaços e possibilidades inventivas e expressivas, de modo a ampliar os limites escolares e criar novas formas de interação artística e de produção cultural, sejam elas concretas, sejam elas simbólicas. (BRASIL, 2017, p. 195)
\end{abstract}

A demais linguagem da disciplina Arte, como dança teatro e música, também possuem um conjunto de características e ações peculiares de sua estrutura; e sabemos que todas estas atividades relacionadas estão diretamente ligadas à criatividade humana, estando elas ligadas ao mundo real ou imaginário.

\begin{abstract}
A importância do ensino de arte na escola sofreu oscilações tendo sido aceito, atualmente, como importante área do conhecimento e desenvolvimento humano, e vem sendo defendido por várias instituições, organizações e grupos de profissionais envolvidos com esse ensino. No Brasil, enquanto república, também houve várias mudanças, tanto de nomenclatura, quanto de objetivos e até mesmo conteúdos lecionados na escola, e que eram da área artística. Fato é que, mesmo com tantas mudanças, na legislação nacional brasileira foi considerada essa importância, do ensino de arte nas escolas, durante as discussões que culminaram na Constituição Federal de 1988, onde já era obrigatória, e, atualmente, pela lei ํำ13. 278/16, que estabelece a arte na educação, composta pelas quatro linguagens artísticas, a saber: Artes visuais, Dança, Música e Teatro. .(BRASIL, 2017, p. 520)
\end{abstract}

trabalho com Artes Visuais com as crianças na educação infantil merece ser trabalhada de forma a ser mais valorizada, pois muito já se sabe que ela representa um estimulo a criatividade e a imaginação, permeando varias etapas do desenvolvimento da criança.

Partindo do princípio que o ensino de Artes visuais tem sido colocado em segundo plano e não tendo a valorização e a importância devida, é importante refletir sobre a sua contribuição na formação da criança, evitando que este valioso instrumento educativo seja considerado um suporte para as outras disciplinas ou um mero passatempo, descaracterizando a importância das artes visuais no processo ensino-aprendizagem.

Barbosa (1989) defende que o caminho para a valorização e sobrevivência é tornar claros os possíveis conteúdos da Arte na escola. Porém, faz-se imperativo 
que o ensino de artes emergindo como conteúdo na escola, deve ser bem trabalhado, com objetivos claros e significativos, oportunizando a criança a aprender e a sentir prazer em aprender, mas o que se vê nas escolas nos dias atuais são alunos desmotivados e sem prazer nos que se refere aos conteúdos relacionados ao ensino de Arte repassado a eles, infelizmente podemos perceber claramente que a um descompasso no caminho para que esse ensino seja prazeroso e motivador. $O$ PCN de artes afirma que:

\begin{abstract}
Aprender com sentido e prazer está associado à compreensão mais clara daquilo que é ensinado. Para tanto, os conteúdos da arte não podem ser banalizados, mas devem ser ensinados por meio de situações e/ou propostas que alcancem os modos de aprender do aluno e garantam a participação de cada um dentro da sala de aula. Tais orientações favorecem o emergir de formulações pessoais de idéias, hipóteses, teorias e formas artísticas. Progressivamente e por meio de trabalhos contínuos essas formulações tendem a se aproximar de modos mais elaborados de fazer e pensar sobre arte. (BRASIL, 1997, p. 35)
\end{abstract}

Andrade (2019) afirma que, Para entrar em relação com saber, o sujeito deve exercer uma atividade, para isso, precisa sentir-se mobilizado, o que implica sentir interesse pelo saber, ou melhor, sentir desejo pelo saber. E destaca ainda que:

\footnotetext{
Para sentir-se desejoso e mobilizado, o saber precisa apresentar-se de maneira significativa, fazer sentindo para a vida do sujeito de alguma forma. Enfim, a relação com o saber se dá quando o sujeito estabelece vínculo entre si e seu objeto de desejo e/ou o seu objeto de conhecimento, traçando meios, movimentando por meio da atividade intelectual para alcançar aquilo que the falta. (ANDRADE, 2019, p. 50)
}

Verifica-se que para a melhoria e a valorização do ensino de Artes, há um longo caminho a percorrer, para tanto se faz necessário um pensar voltado para a formação dos profissionais, para o sistema educacional entre outros que podem interferir no planejamento e na prática desse ensino nas escolas.

Barbosa (2014) Alerta para os problemas relacionados à formação e o preparo dos professores de Artes. Segundo a autora existem professores dando aulas de arte que nunca leram nenhum livro sobre arte-educação e pensam que arte na escola é dar folhas para colorir com corações para o Dia das Mães, soldados no Dia da Independência, e assim por diante. Infelizmente essa é uma realidade, professores atuando na área sem preparo algum, tratando o ensino de Artes como a hora do lazer e da descontração das crianças. 
O componente curricular Arte deve ser trabalhado em toda sua amplitude de forma que o estudante se situe no mundo e perceba as diferenças humanas e culturais e suas inter-relações, conhecendo, reconhecendo, interpretando, reinterpretando e apropriando-se delas em aspectos das manifestações artísticas e estéticas. Deve articular, portanto, manifestações culturais de tempos e espaços diversos englobando o entorno cultural e artístico do estudante, as produções passadas e contemporâneas, de forma histórica, social e política, propiciando entendimento dos costumes e valores culturais, e que aliam-se ao desenvolvimento das competências gerais, ou seja, a formação integral do ser em desenvolvimento.(BRASIL, 2017 p. 520,521)

Educar mediante o ensino da Arte visual é proporcionar ao aluno um mundo de possibilidades, disponibilizando a eles o acesso a diferentes materiais e formas existentes ou que possam ser criados através da pintura, da modelagem, e da escultura entre outros, permitindo a criança experimentar através da Arte visual um processo que permita a ela a construção e a desconstrução o fazer e o refazer; fazendo com que a criança viva o prazer da imaginação e da criatividade não se prendendo a algo predefinido pelo professor e sim permitindo ao aluno chegar ao final de cada projeto com um trabalho que mostre o fruto de sua imaginação e de sua sensibilidade; não algo engessado, uniforme igual a todos do grupo; pois educar em arte é manter a criança livre para se expressar, através de seu corpo, linhas e pinceladas, ideias, sentimentos e capacidades, possibilitando a ela 0 desenvolvimento de sua autonomia, autoestima e segurança para expressar seus pensamentos e ideias. Para, Martins, Picosque, Guerra (1998, p, 136) A linguagem visual também pode ser revelada a criança através de um olhar sensível olhar pensante. $\mathrm{O}$ olhar já vem carregado de referencias pessoais e culturais: Contudo é preciso ainda que se busque instigar o aprendiz a um olhar cada vez mais curioso e sensível no que se refere à linguagem visual. Martins, Picosque, Guerra (1998)

\begin{abstract}
Essas competências e habilidades, essenciais para a formação humana, cuja arte pode desenvolver e potencializar em cada estudante devem ser trabalhadas nas diversas linguagens do presente componente curricular, e que na Base Nacional Comum Curricular (BNCC) e no Currículo Referência de Minas Gerais, vêm descritos como unidades temáticas. Ao longo do Ensino Fundamental, os estudantes devem expandir seu repertório e ampliar sua autonomia nas práticas artísticas, por meio da reflexão sensível, imaginativa e crítica sobre os conteúdos artísticos e seus elementos constitutivos e também sobre as experiências de pesquisa, invenção e criação (BRASIL, 2017, p. 520,521)
\end{abstract}

É possível verificar que o ensino de Artes visuais é de suma importância para a formação humana, mas infelizmente a desvalorização e a banalização 
referente à disciplina e ao ensino dela acabam se tornando uma barreira, que deve ser rompida para que essa valorização e a melhoria desse ensino aconteçam, E vale ainda ressaltar que esta desvalorização do ensino de Arte não se da apenas entre os profissionais que a atuam na área, mas também entre a comunidade e familiares do educando, é preciso que seja esclarecido que a Arte está presente na sociedade em profissões que são exercidas nos mais diferentes ramos de atividades; o conhecimento em artes é necessário no mundo do trabalho e faz parte do desenvolvimento profissional dos cidadãos, afirma: PCNs (Brasil, 1997). Para tanto se deve buscar trabalhar essa temática de forma que a torne mais significativa, e menos desprivilegiada, pois assim como português e matemática e os outros componentes da matriz curricular tem sua importância; sem o ensino de Artes visuais, afirma: Barbosa (2014, p. 5) Não é possível o desenvolvimento de uma cultura sem o desenvolvimento das suas formas artísticas.

\footnotetext{
Não é possível uma educação intelectual, formal ou informal, de elite ou popular, sem arte, porque e impossível o desenvolvimento integral da inteligência sem o desenvolvimento do pensamento divergente, do pensamento visual e do conhecimento presentacional que caracterizam a arte. (BARBOSA, 2014, p. 05)
}

Para tanto é preciso buscar essa valorização, Barbosa (2014 p. 5) destaca a importância de buscarmos arte + educação + ação e pesquisa para descobrir como nos tornarmos mais eficientes no nosso contexto educacional desenvolvendo o desejo e a capacidade de aprender de nossas crianças.

Entende-se aqui, para que essa valorização possa ocorrer é necessário que se busque trabalhar o ensino de Artes visuais de forma prazerosa sim, mas buscando dar significado ao trabalho realizado em sala de aula, trabalhar contextos nos quais os alunos possam compreender o ensino de Arte em todos os seus aspectos.

\subsection{Preparo profissional}

Assim como em qualquer outro componente da grade curricular o ensino de Artes visuais, também necessita de atenção no que diz respeito ao preparo profissional, mas infelizmente nos deparamos com um quadro totalmente diferente a respeito do ensino de Artes nas escolas, como professores que ministram a disciplina que não tem formação na área, geralmente são formados em pedagogia, 
possuindo um breve estudo no que se refere ao ensino de Artes. Contudo se faz necessário, mesmo que não haja investimento em profissionais da área de Artes é de grande importância que o professor atuante busque um conhecimento mínimo para atuação no ensino de Artes, como também, planejamentos mais elaborados para as aulas que serão ministradas, e no que diz respeito à instituição escolar, buscar formas de capacitação para os professores que ministram essa disciplina. Esse preparo se faz necessário podendo mostrar a importância que o ensino de artes tem dentro do currículo escolar e dentro da própria escola, outra maneira em que o ensino de artes pode ser trabalhado é na contemplação de possíveis projetos no PPP (Projeto Politico Pedagógico) da escola a fim de abranger a Arte como foco principal, mostrando ao professor, comunidade, como também para os familiares dessas crianças, a real importância de se trabalhar a Arte, Barbosa (2014 p. 2) afirma que a arte na educação afeta a invenção, inovação e difusão de novas ideias e tecnologias, encorajando um meio ambiente institucional inovado e inovador. Podendo assim Mudar então a visão em que o ensino de Artes esta relacionado, como relata os PCNs (1997, p. 26) existe uma espécie de circulo vicioso de um sistema pobre de formação, reforçando o pouco espaço que da área de Artes, relacionadas às outras disciplinas do currículo escolar.

\footnotetext{
Sem uma consciência clara de sua função e sem uma fundamentação consistente de arte como área de conhecimento com conteúdos específicos, os professores não conseguem formular um quadro de referências conceituais e metodológicas para alicerçar sua ação pedagógica; não há material adequado para as aulas práticas, nem material didático de qualidade para dar suporte às aulas teóricas. A partir dessas constatações procurou-se formular princípios que orientem os professores na sua reflexão sobre a natureza do conhecimento artístico e na delimitação do espaço que a área de Arte pode ocupar no ensino fundamental, a partir de uma investigação do fenômeno artístico e de como se ensina e como se aprende arte. (BRASIL, 1997, p. 26)
}

Para tanto é preciso que haja comprometimento com o ato de ensinar, buscando formas que vise uma melhor atuação por parte do professor e da escola. O papel dos professores é importante para que os alunos aprendam a fazer Arte e gostar dela ao longo da vida. Tal gosto por aprender nasce também da qualidade da mediação que os professores realizam entre os aprendizes e a Arte, destaca lavelberg (2010, p. 10) é necessário que se tenha vontade de agir de forma diferente, como questiona Barbosa (2014, p. 2) será que Arte é somente um quadro para pendurar na parede? É partindo desse pressuposto e de como o ensino de 
Artes visuais pode ir muito mais além, é que podemos mostrar para nossas crianças, as diversas formas de Artes visuais e de como ensinar e aprender através delas, principalmente as artes que estejam ao seu redor. E como uma boa e motivadora escolha em relação a essas diversas formas de se trabalhar o ensino de Artes, é a promoção de trabalhos realizados na sala de aula voltados para conteúdos relacionados ao ambiente de origem e cotidiano dos alunos, valorizando assim o universo cultural, incentivando a preservação da cultura e criando em cada aluno o sentimento de orgulho da própria cultura de origem e de respeito à cultura dos outros, gerando uma relação não preconceituosa com a diversidade das culturas, (IAVELBERG, 2010, p. 12).

É importante que se explore a cultura e o ambiente em que elas estão inseridas, pois ensina-se a gostar de aprender arte com a própria arte em uma orientação que visa a melhoria das condições humana, em uma perspectiva de promoção de direitos na esfera das culturas (criação e preservação), sem barreiras de classe social, sexo, raça , religião e origem geográfica, afirma lavelberg (2010, $\mathrm{p}, 12$ ) assim como forma de trabalho podemos, ressaltar o artesanato local a arte popular, entre tantas outras formas de Artes visuais que podem ser exploradas; e partindo desse interesse e da pesquisa incessante, o professor e a escola começarão a mudar a imagem do ensino da arte. Barbosa destaca que:

\footnotetext{
Arte não é apenas básica, mas fundamental na educação de um país que se desenvolve. Arte não é enfeite. Arte é cognição é profissão, é uma forma diferente da palavra pra interpretar o mundo, a realidade, o imaginário, e é conteúdo. Como conteúdo, a Arte representa o melhor trabalho do ser humano. Arte é qualidade e exercita nossa habilidade de julgar e de formular significados que excedem nossa capacidade de dizer em palavras. É o limite da nossa consciência excede o limite das palavras. (BARBOSA, 2014, p. 04)
}

O ensino de Artes visuais requer não somete, comprometimento, mas também paixão e fascínio por aquilo que o educador se propõe a fazer. Martins, Picosque, Guerra (1998, p. 129) refere-se ao educador como, aquele que prepara uma refeição, que propõe a vida em grupo, que compartilha o alimento que celebra $o$ saber. É do entusiasmo do educador que nasce o brilho dos olhos dos aprendizes. Brilho que reflete também o olhar do mestre. Podemos também entender cada aula, como um jogo de aprender e ensinar, que requer preparação e coordenação, um instante mágico. Conduzido por mãos habilidosas que tocam que apontam que 
escolhem contextos significativos para a vida do aluno, Martins, Picosque, Guerra (1998, p. 129)

\begin{abstract}
A magia certamente pode ser facilitada pelo cenário da sala de aula e por aprendizes vorazes pelo aprender. Mas o magico educador, muitas vezes é limitado pelas amarras que lhe são impostas no espetáculo da vida, terá de encontrar saídas na busca incessante do que é possível, para além do apenas aceitável. (MARTINS; PICOSQUE; GUERRA, 1998, p. 129,130)
\end{abstract}

Contudo é preciso que se ultrapassem as barreiras e dificuldades impostas ao ensino de Arte visual, buscando não apenas solução no modo como se é transmitido esse ensino, mas também um reconhecimento para essa área da educação tão desprivilegiada, mas de importância ímpar ao desenvolvimento do educando.

Entende-se aqui a necessidade de uma educação que dê ênfase às Artes visuais, pois a preocupação com a qualidade deste ensino deve estar presente em todas as esferas da instituição escolar, da sala de aula aos gabinetes do diretor e coordenadores, Smith (1986, p. 98), portanto, a escola necessita não somente estimular os professores como também buscar esse estímulo, apontando essa necessidade, e buscando preparação para essa ação, visto que a escola é uma instituição viva, com transformações constantes, daí entender que esse preparo não constitui uma capacitação única, mas de maneira continuada.

\title{
3. O desenvolvimento da criança através da arte
}

É inegável a contribuição que o ensino de Arte traz para o desenvolvimento da criança nos anos iniciais do ensino fundamental, Prosser (2012) relata que ao examinar o papel da Arte no processo educativo da criança, vemos que ela, além de ser veículo de expressão do pensar e do sentir da criança, é mediadora do aprendizado relativo tanto ao seu mundo interno quanto externo, por isso pode-se afirmar que é de grande importância que esse processo de incentivo a educação em Artes seja trabalhado da melhor forma possível e de preferencia logo que a criança inicia sua vida escolar, pois é do saber de todos, que a Arte já esta inserida na vida da criança desde muito cedo, ela já se relaciona com a Arte mesmo antes de estar na escola, como afirma Prosser: 
Se nos perguntarmos quando devemos iniciar as atividades artísticas na educação, vemos que a criança já as realiza desde que nasce: quando bem pequena ouvi a mãe falar e cantar, dialoga e canta com ela, com suas interjeições; com poucos meses, já se movimenta ao ritmo da musica: logo consegue pegar um lápis e rabiscar o papel e a parede os moveis... (PROSSER, 2012, p. 7)

Nesse contexto cabe ao professor, no entanto, explorar a pratica da Arte no processo de desenvolvimento da inteligência, do aprendizado e das relações humanas, tanto como atividade racional quanto como necessidade social. Prosser (2012, p, 16) Ao chegar à escola a criança já trás consigo uma bagagem emocional e cultural relacionada à Arte que faz parte do seu universo afetivo-cognitivo estimulado pelo ambiente em que ela vive, e que pode ser facilmente percebido quando ela desenha, pinta, canta, dança, representa, entre outras formas que a criança apresente, ela estará representando aquilo é importante, e que tem significado para ela e certamente precisa ser valorizado Prosser $(2012$, p. 6) a Arte pode ser considerada uma expressão do universo cognitivo e afetivo de cada um, pois revelamos o que sentimos e pensamos quando trabalhamos com ela, por esse motivo a contextualização a motivação e o estímulo necessitam ser constantes por parte do professor. E não somete um aprendizado acumulado sem sentido algum como destaca:

\begin{abstract}
O professor derrama informações sobre o aluno, que apenas repete o que ouviu, sem refletir, sem questiona, sem relacionar essas informações com a realidade em que vive. O professor ainda ensina a desenhar como o mundo adulto acha que a criança deve desenhar, ensina a cantar aquilo que e de maneira que 0 adulto quer que ela cante. Não leva em conta as fases de desenvolvimento da criança, tampouco, suas necessidades, sua criatividade, sua curiosidade. O centro do processo é o professor que conhece e transmite o seu conhecimento. (PROSSER, 2012, p. 8)
\end{abstract}

Contudo pode-se relacionar a Arte a um conhecimento necessário para formação da criança, lavelberg (2010, p. 9) destaca que a arte promove o desenvolvimento de competências, habilidades e conhecimento necessários a diversas áreas de estudos; entretanto, não é isso que justifica sua inserção no currículo escolar, mas seu valor intrínseco como construção humana, como patrimônio comum a ser apropriado por todos. A Arte permeia a vida e o cotidiano de cada indivíduo, estando também relacionada à sua cultura, dando sentido às experiências vividas. 
A Arte tem papel fundamental na recuperação da cultura dos alunos, favorecendo sua identificação com os conteúdos de aprendizagem. lavelberg (2010, p. 22) E partindo desse pressuposto cabe ao professor transformar essas particularidades de cada aluno em produções criativas, podendo envolver o aluno, familiares e comunidade no processo de criação tornando-os parte de cada projeto, pois quanto mais o aluno tiver oportunidade de ressignificar o mundo por meio da especificidade da arte, mais poder de percepção sensível, memórias significativas e imaginação criadora ele terá para formar consciência de si mesmo e do mundo como afirma, Martins, Picosque, Guerra (1998, p. 129)

\begin{abstract}
A educação em arte propicia o desenvolvimento do pensamento artístico, que caracteriza um modo particular de dar sentido às experiências das pessoas: por meio dele, o aluno amplia a sensibilidade, a percepção, a reflexão e a imaginação. Aprender arte envolve, basicamente, fazer trabalhos artísticos, apreciar e refletir sobre eles. Envolve, também, conhecer, apreciar e refletir sobre as formas da natureza e sobre as produções artísticas individuais e coletivas de distintas culturas e épocas. (BRASIL, 1997 p. 15)
\end{abstract}

Entende se aqui que o ensino de Artes em todas as suas linguagens deve ser trabalhado de forma a propiciar melhorias na vida das crianças, buscando propostas de ensino a fim de promover a educação ética, formação para a cidadania participativa e de recuperação da autoestima dos educandos considerados cidadãos com direito a cultura e a educação. lavelberg (2010)

\title{
4 Considerações finais
}

O desenvolvimento deste estudo possibilitou uma análise de como o ensino de Artes visuais vem sendo ministrado nas escolas nos anos iniciais do ensino fundamental propiciando também uma reflexão acerca da valorização, dificuldades e benefícios encontrados ao trabalhar essa disciplina.

Buscou-se verificar se o ensino de Artes visuais tem a mesma valorização no que se referem as demais disciplinas do currículo escolar, como também salientar a falta de preparo referente aos profissionais que ministram essa disciplina, e a importância dela para o desenvolvimento da criança.

Mediante a pesquisa realizada percebeu-se um grande avanço na atual situação do ensino de Artes, tendo sua importância e valorização defendida por 
varias organizações, instituições, e grupo de profissionais envolvidos com o ensino como afirma o Currículo Referencial de Minas Gerais.

Contudo no que se refere ao ensino de Artes, relacionado à sua importância e valorização dentro do currículo escolar, ainda a uma logo caminho a percorrer, de forma que haja um maior comprometimento com o ato de ensinar, compreensão por parte da instituição escolar buscando preparar melhor os professores responsáveis por essa atuação e que esses profissionais também busquem essa capacitação para ministrar a disciplina no sentido de dar significado e devido valor, não tratando essa disciplina que muito tem a oferecer para os nossos alunos, como mero passatempo ou momentos para colorir ou ilustrar as datas comemorativas ao longo do ano letivo, impedido o avanço dos alunos em relação ao que pode ser aprendido, desconsiderando habilidades que os alunos já possuam ou que podem ser adquiridas ou ate mesmo aprimorados.

Conforme os referenciais teóricos analisados o ensino de Artes tem um papel significativo relacionado ao desenvolvimento da criança nos anos iniciais do ensino fundamental propiciando à aprendizagem, criatividade, imaginação, sensibilidade, percepção de si mesmo e do outro. Possibilitando também o conhecimento relacionado à cultura do ambiente em que ele esta inserido, como também as culturas existentes, favorece o desenvolvimento de aspectos sociais, tornando-o individuo crítico, pensante capaz de se relacionar e de maneira criativa resolver possíveis problemas.

Enfim, mesmo com todos os avanços e melhorias relacionados ao ensino de Artes ainda se faz emergente um pensar voltado para a consolidação dessa disciplina como instrumento necessário no contexto escolar e para o desenvolvendo do educando.

Diante do exposto conclui-se que o ensino de Artes deve ser trabalhado de forma igualitária referente às outras disciplinas do currículo, dando a ela a devida importância, no sentido de elevar essa disciplina a um nível mais alto, permitindo que ela seja vista como um potencializador do desenvolvimento da criança, e não um mero passatempo ou a hora do lazer das crianças, permitindo assim dar sentido aos trabalhos realizados em sala de aula.

\section{Referências}


ANDRADE, Alcilene Lopes de Amorim A dimensão relacional do (não) aprender / Alcilene Lopes de Amorim 2019 Andrade, Jéssica Rodrigues Lima. - 1. ed. - Curitiba: Appris, 2019.

BARBOSA, Ana Mae. A imagem do ensino da arte: anos 1980 e novos tempos. São Paulo: Perspectiva, 2014.

BARBOSA, Ana Mae. Arte-Educação no Brasil: realidade hoje e expectativas futuras. Estudos Avançados, v. 3, n. 7, p. 170-182, 1 dez. 1989. Disponível em: <http://www.revistas.usp.br/eav/article/view/8536> Acesso em: 27 de abril de 2019.

BRASIL, Currículo Referência de Minas Gerais. 2018. Disponível em: <http://www2.educacao.mg.gov.br/images/documentos/20181012\%20\%20Curr\%C3 \%ADculo\%20Refer\%C3\%AAncia\%20de\%20Minas\%20Gerais\%20vFinal.pdf>. Acesso em: 29 de abril de 2019.

BRASIL, Currículo Referência de Minas Gerais. Secretaria de Estado de Educação de Minas Gerais - SEE/MG e a União Nacional dos Dirigentes Municipais de Educação, seccional Minas Gerais UNDIME/MG. Disponível em: $<$ http://www2.educacao.mg.gov.br/transparencia/story/9947-see-apresenta-versaopreliminar-do-curriculo-de-minas-gerais-a-servidores> Acesso em: 11 de março de 2019.

BRASIL, $O$ ensino de Arte e a sua finalidade: Educação infantil e anos iniciais do ensino fundamental. Disponível em: $<$ https://educere.bruc.com.br/arquivo/pdf2017/23809_11871.pdf> Acesso em: 28 de agosto de 2018.

BRASIL, Relevância do trabalho com Artes nos anos iniciais do Ensino Fundamental: Exercício continuo da imaginação. Disponível em: $<$ https://educere.bruc.com.br/ANAIS2013/pdf/9854_6948.pdf> Acesso em: 28 de setembro de 2018 .

BRASIL, Parâmetros Curriculares Nacionais: Arte / Secretaria de Educação Fundamental. - Brasília: MEC/SEF, 1997. Disponível em: <file:///C:/Users/Vss/Desktop/tcc2019\%20atual/pcn\%20de\%20arte.pdf> acesso em 14 de junho de 2019.

BRASIL, Parâmetros Curriculares Nacionais: Arte / Secretaria de Educação Fundamental. - Brasília: MEC/SEF, 1997. Disponível em: < $<$ http://portal.mec.gov.br/seb/arquivos/pdf/livro06.pdf> acesso em 14 de junho de 2019.

BRASIL, Base nacional comum curricular: Arte. Ministério da Educação 2017 Disponível em: $<$ http://basenacionalcomum.mec.gov.br/images/BNCC_EI_EF_110518_versaofinal_s ite.pdf >acesso: em 24 de maio de 2019

IAVELBERG, Rosa. Para gostar de aprender arte; sala de aula e formação de professores. Porto Alegre; Artmed, 2010. Disponível em: 
$<$ https://books.google.com.br/books?id=BCALtgYz4ylC\&printsec=frontcover\&hl=pt$\mathrm{BR}>$ acesso em 28de maio de 2019.

MARTINS, Mirian Celeste; PICOSQUE, Gisa; GUERRA, Maria. Terezinha Telles. Didática do ensino de arte: a língua do mundo: poetizar, fruir e conhecer arte. São Paulo: FTD, 1998.

PINTO, Mariane Danielle Sousa, 0 ensino de Arte nos anos iniciais do Ensino Fundamental: Especialização em Ensino de Artes Visuais, 2015. Disponível em: $<$ http://www.bibliotecadigital.ufmg.br/dspace/bitstream/handle/1843/BUBDA9GGCP/mariane__monografia_artes_.pdf?sequence=1 > acesso: em 29 de setembro de 2018.

PROSSER, Elisabeth Seraphim. Ensino de Artes. 1. ed. Curitiba: IESD, 2012. Disponível em:

$<$ https://books.google.com.br/books?id=uH4wfO0tR1EC\&printsec=frontcover\&hl=ptBR> acesso em: 30 de maio de 2019.

SMITH, Ralph. Excelência no Ensino da Arte. Trabalho apresentado em sessão especial da NADA (associação nacional de Educação Artística_ USA), em encontro New Orleans (Abril 1986. Trad. Fundação lochpe. BARBOSA, Ana Mae (Org.). Arteeducação: leitura no subsolo. 2 .ed. São Paulo: Cortez, 2011. 